\title{
Evaluation of bus transfer stations from the passenger's point of view
}

\author{
S. Basbas \\ Department of Transportation and Hydraulics Engineering, \\ Faculty of Rural and Surveying Engineering, School of Technology, \\ Aristotle University of Thessaloniki, Greece
}

\begin{abstract}
Bus transfer stations play a key role in the overall performance of the public transport system. Within the framework of this paper the profile of passengers who use bus transfer stations together with their evaluation of the services and infrastructure provided at these stations is presented and discussed. In addition, results concerning the overall evaluation of the Public Transport system are also presented. These results are obtained through the use of questionnaire-based surveys that took place in the city of Thessaloniki, Greece. Results have shown that passengers' priorities vary according to whether they are car owners or not. Results also show that the provision of information is much more important to passengers at bus transfer stations than to the rest of the bus passengers.

Keywords: bus transfer station, public transport evaluation, passenger needs.
\end{abstract}

\section{Introduction}

Bus transfer stations play a key role in the overall performance of the public transport system. The evaluation of the level of the Public Transport (PT) services by the passengers is usually made through the use of questionnairebased surveys. Factors, which affect the opinion of the passengers about the level of service, vary from one city to another depending on the special characteristics of the PT system and the local conditions. It is very interesting to see, diachronically, there are specific factors (like bus passenger waiting time), which constantly appear in the results of such surveys. It must be mentioned at this point that "From the passenger's point of view, the onerous part of transferring is waiting for the connecting bus. Many transit agencies provide shelters, transfer 
centers, and public information to afford more certainty for the passengers" [1]. It is also well known that the need to transfer to another vehicle is considered more or less as a penalty by the passengers. This is the reason why the number of bus transfers should not exceed one for the $95 \%$ of the trips daily made by buses and two for the rest $5 \%$ of the trips daily made by buses [2]. From the examination of the inconvenience factors relating to the use of PT in Coventry [3] it was found that the percent primacy of the most important factors as reported by non-car owning people was as shown below: $23.6 \%$ bus stop too far from residence, $19.5 \%$ too long to wait for bus, $17.2 \%$ having to transfer to another vehicle, $14.6 \%$ no shelter at bus stops and $13.0 \%$ not being certain of seat on bus. According to a questionnaire-based survey which concerns the bus transit system in metropolitan Kuwait [4] the noise inside the bus (20.7\%), long travel time (low speed) (19.4\%), lack of air conditioning in the bus $(18.2 \%)$, discomfort (12.2\%) and long headways (waiting time) (10.5\%) ranked first, second, third, fourth and fifth respectively, as factors contributing most to the dissatisfaction of the riders. Four stages of the intermodal transfer can be identified [5]: a) the approach to the facility and the quality of service to reach the terminal, b) a transferring passenger must go through some sort of ticketing process, c) the actual transfer itself (locating the new vehicle, waiting time, physical qualities of the terminal) and d) departure from the terminal. Within the framework of this paper the profile of passengers who use bus transfer stations together with their evaluation of the services and infrastructure provided at these stations is presented and discussed. The results presented are based on various questionnaire-based surveys, which took place in Thessaloniki, Greece.

\section{Questionnaire-based survey characteristics}

Public Transport system in Thessaloniki includes the Urban Transport Organisation of Thessaloniki (OASTH) which is the bus operator for urban transport. OASTH daily operates 68 bus lines in its network with 505 buses (out of the 536 buses of the fleet). The number of passengers annually served is in the area of $150,000,000$ [6]. The reformation of the Thessaloniki bus network created the need to operate two main bus transfer stations, one in the western part and one in the eastern part of the city. The first bus transfer station (western part of the city) is known as "New Railway Station - NRS" since it is located in an area nearby the Railway Station. The NRS bus transfer station served 17 bus lines during the survey period while the IKEA bus transfer station served 7 bus lines during the same period. The second bus transfer station (eastern part of the city) is known as the "IKEA station" since it is located in the area of the IKEA store. Schedule time depends on the length of each bus line (the first bus started its operation in the period 04:00-05:15 and the last bus in the period 24:2201:35). Another bus transfer station is located in the Thessaloniki's "MAKEDONIA" International Airport. The airport was served by one bus line during the period of the survey. This specific bus line (No.78) has a length of around $17 \mathrm{~km}$ and it connects the city and the interurban coach station KTEL with the airport. The bus line operation started at 05:25 from the KTEL station 
and the last bus leaves the airport at 23:00. There are 4 buses into operation and the average service frequency is 34.5 minutes. Bus fare was 0.5 euro while the cost of the taxi for the same trip was in the area of 6 euros. The questionnairebased survey concerning passengers' profiles and opinions at the NRS and IKEA stations was carried out in the framework of the research activities of the Department of Transportation and Hydraulic Engineering, Faculty of Rural \& Surveying Engineering, Aristotle University of Thessaloniki [7]. The survey was carried out during May-June 2003 and 140 valid questionnaires were collected (90 referred to the NRS station and 50 to the IKEA station). The respective questionnaire-based survey concerning the Thessaloniki "Makedonia" Airport was also carried out in the framework of the same department [8]. The survey was carried out in July 2003 and 563 valid questionnaires were collected.

\section{Passenger profile at bus transfer stations}

\subsection{Passenger profile at the NRS bus transfer station}

The distribution of the various categories of passengers is presented in Figure 1. Employees constitute more than $1 / 3$ of the passengers. Almost $1 / 4$ of the passengers are university students. In addition there are $7 \%$ of the passengers who are highschoolers. This means that at least $30 \%$ of the passengers are young people (secondary education or university). Significant percentages (15\%) are pensioners while $18 \%$ of the passengers are classified as "other". The distribution of trip purpose per passenger category is presented in Figure 2. "Return home" constitutes the basic trip purpose followed by "personal affairs" (e.g., visit to a doctor). "Shopping", "business" and "education" are characterized by relatively small percentages $(6 \%, 8 \%$ and $10 \%$ respectively). A possible explanation for the low percentage of "shopping" is that people carrying shopping bags usually prefer not to change transport modes if they can.

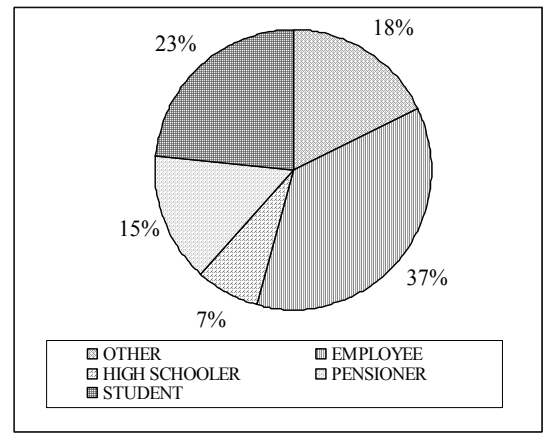

Figure 1: Categories of passengers.

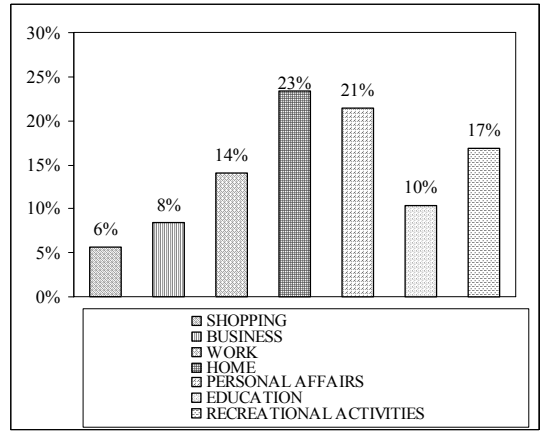

Figure 2: $\quad$ Trip purpose per passenger category.

The results from the examination of the trip purpose distribution per category of passengers show that employees mainly use the bus transfer station for 
"work" purpose. The respective trip purposes for highschoolers is "education", for students are "education" and "home" and for pensioners is "home". Results seem to be reasonable in general and they also show that peak periods, as far as bus schedules are concerned, can be predicted for certain population groups like employees, highschoolers and students who have fixed working hours. The frequency of the use of the specific bus transfer station by passengers who own a private car is also examined within the framework of the survey. A percentage of $23 \%$ of these passengers have stated that they use the bus transfer station twice a day. Therefore almost $1 / 4$ of the total daily number of passengers are private car owners who, for their own reasons, prefer to use the bus transfer station for at least two trips per day.

\subsection{Passenger profile at the IKEA bus transfer station}

The distribution of the various categories of passengers is presented in Figure 3. Employees constitute 1/3 of the total number of passengers who use the specific bus transfer station as they did in the case of the NRS station. Almost 1/4 of the passengers are students at university as it also appeared in the case of the NRS station. In addition to this percentage there is a $15 \%$ of the passengers who are highschoolers. This means that at least $41 \%$ of the passengers are young people (secondary education or university). The twofold percentage of the highschoolers compared to the one observed at the NRS station can be possibly explained by the fact that the IKEA station serves a number of built-up areas around the city of Thessaloniki and consequently serves the respective trips to and from the high schools located in the city. Significant percentages $(17 \%)$ are pensioners while $9 \%$ of the passengers are classified as "other". Therefore, the categories of the passengers are more or less similar in the two bus transfer stations under examination, with the exception of the highschoolers. The distribution of trip purposes per passenger category is presented in Figure 4. "Work", "return home" and "education" constitutes the basic trip purposes (73\% in total). Surprisingly, "shopping" does not exist as a trip purpose, something that shows that people use their private cars in order to access the bus transfer station greater area, which is characterized by the existence of a large number of stores.

The results from the examination of the trip purpose distribution per category of passengers show that employees mainly use the bus transfer station for "work" purpose. This percentage is twice as much the one observed in the NRS station. The respective trip purpose for highschoolers is "education", for students is "education" and "home" and for pensioners is "home". Results also show that peak periods, as far as bus schedules are concerned, can be predicted for certain population groups like employees, highschoolers and students. Concerning the frequency of the use of the specific station by passengers who own a private car, the situation is completely different from the one observed in the NRS station. More specifically, 64\% use the IKEA station twice a day (compared to the respective $23 \%$ in the NRS station).

Therefore almost $2 / 3$ of the total daily passengers are private car owners who, for their own reasons, prefer to use the bus transfer station for at least two trips per day. 


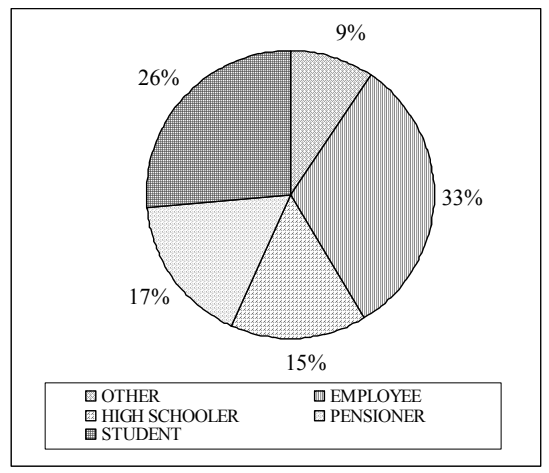

Figure 3: Categories of passengers.

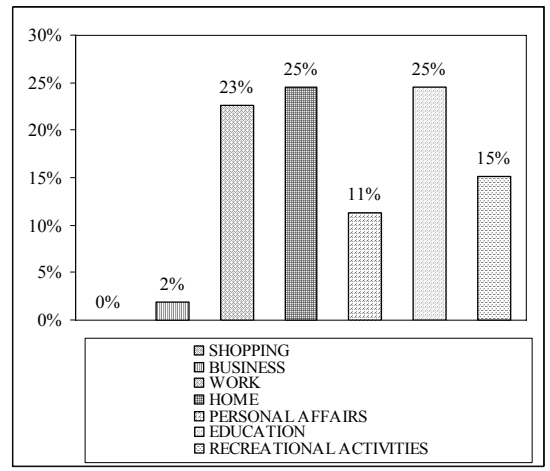

Figure 4: Trip purpose per passenger category.

\subsection{Passenger profile at the Thessaloniki "Makedonia" airport}

The distribution of transport mode used by passengers who are private car owners is presented in Figure 5. More than half of the passengers use their own private cars to access the Thessaloniki "Makedonia" Airport while 37\% use a taxi. Only a small percentage (5\%) use PT buses while $4 \%$ use a rental car. Therefore around $95 \%$ of the passengers use a car (private, rental or taxi) for their trip. The distribution of transport mode used by passengers who are not private car owners is presented in Figure 6. The respective percentage of passengers using a car (private, rental or taxi) is $88 \%$ while the percentage of passengers using a PT bus is again very low (8\%). It is clear form these results that the vast majority of passengers are not in favor of a PT bus when they are travelling to and from the airport. The dominant role that private cars and taxis play is clearly presented in these figures.

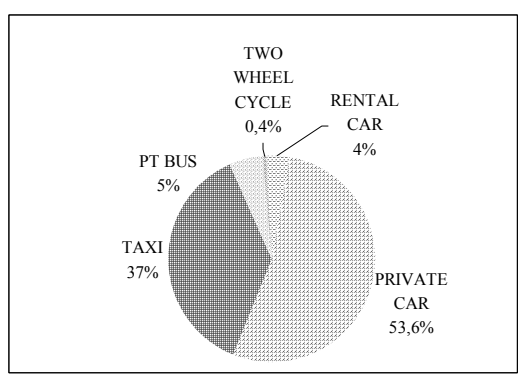

Figure 5: Transport mode used to the airport (car owners).

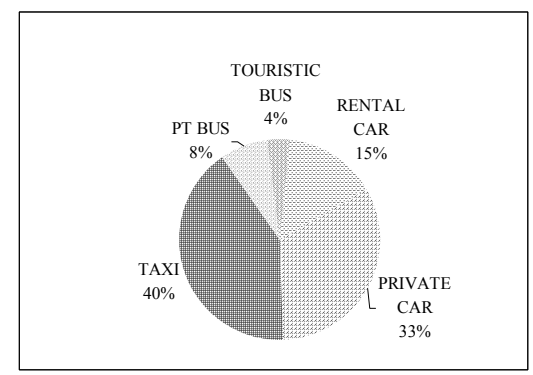

Figure 6: Transport mode used to the airport (non-car owners).

In the Thessaloniki "Makedonia" Airport survey, 68\% of the passengers stated that they would use a PT bus regardless the transport mode they had used in the day of the survey. It is obvious that people would use PT to a certain 
extent $(2 / 3$ of them) under specific conditions. The impact of the "annual income" in passengers' decision of whether to use public transport bus or not is presented in Figures 7 and 8. The results show that, in general, people who had stated that they would not use PT are characterized by a bit much higher income compared to those who stated the opposite.

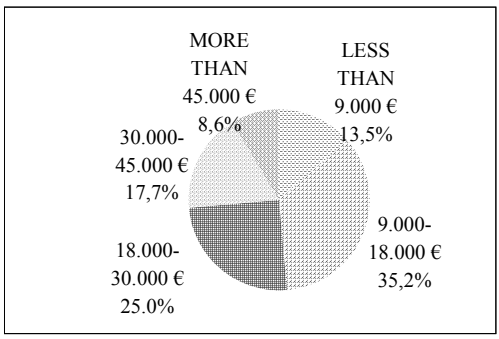

Figure 7: Income distribution for use PT.

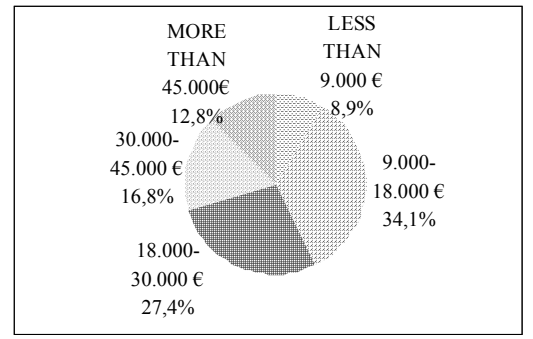

Figure 8: Income distribution for passengers who would not use PT.

\section{Evaluation of bus transfer stations and the PT system}

Figure 9 presents the factors that would positively affect the choice of PT to and from the Thessaloniki "Makedonia" Airport (all passengers included regardless the transport mode they used in the day of the survey). "Reliability" and "frequency" play a very important role in people's choice of PT. "Comfort" and "direct service" also seriously affect people's choice. These results can be explained by the fact that time and comfort play an important role for passengers who travel to or from an airport. Finally almost $1 / 3$ of the passengers think of "better information", "night trips" and "trip time" as essential preconditions in order to ride on a PT bus.

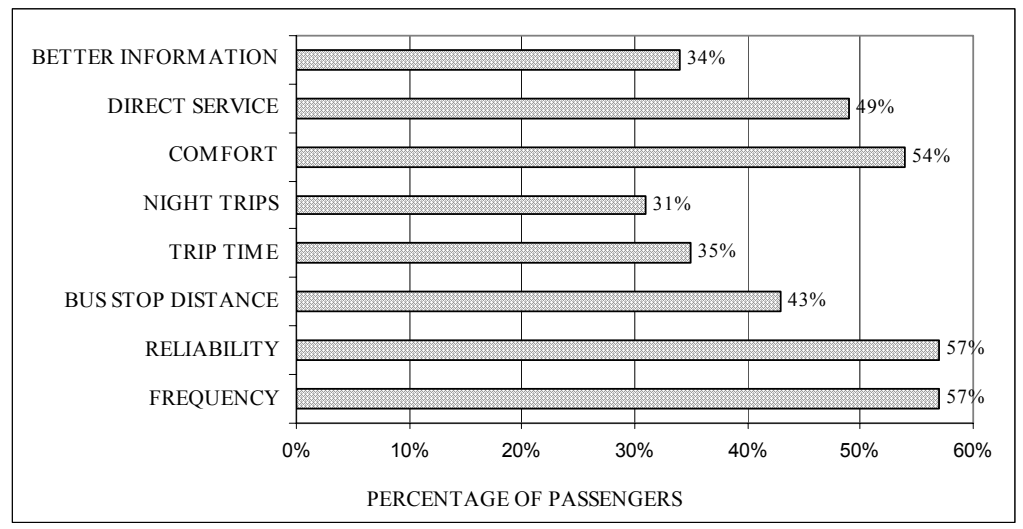

Figure 9: Factors that would positively affect the choice of PT to and from the Thessaloniki "Makedonia" Airport. 
It is worthwhile to present at this point the opinion of the city residents about the level of service offered by the PT system during the period 1988-98 (Table 1). These results were based on extensive home-based questionnaires surveys carried out in the year 1988 (9237 questionnaires) and in the year 1998 (3326 questionnaires) [9, 10]. As shown in this Table, during the period 1988-98 there was an increase in the number of people who believed that the level of service of the PT system is satisfactory or quite satisfactory. At the same time, the percentage of people using PT is decreasing. Even though, it seems that bus priority measures introduced in the city during that period did not seriously affect modal split in favor of PT.

Table 1: $\quad$ Level of PT services as perceived by the city residents.

\begin{tabular}{|l|c|c|}
\hline Level of service & Year 1988 & Year 1998 \\
\hline Satisfactory & $7.2 \%$ & $20.4 \%$ \\
\hline Need for small improvements & $19.3 \%$ & $18.2 \%$ \\
\hline Need for substantial improvements & $49.2 \%$ & $34.1 \%$ \\
\hline Unacceptable & $24.3 \%$ & $27.3 \%$ \\
\hline
\end{tabular}

Table 2 presents the factors that would positively affect the choice of PT for bus passengers and for car drivers in Thessaloniki according to a questionnairebased survey, which was carried out in the framework of the M.Sc Course on Design, Organisation and Management of Transport Systems, Aristotle University of Thessaloniki [11] concerning the characteristics of trips and passengers in Thessaloniki. The survey took place during the period July-August 2004 and 200 valid questionnaires were collected (135 from bus passengers and 65 from car drivers). The interviews of the car drivers took place outside parking stations located near bus stations. Bus frequency, comfort and travel time seem to play an important role for bus passengers.

Table 2: $\quad$ Factors that would positively affect the choice of PT for passengers using PT in Thessaloniki and for car drivers (number of answers).

\begin{tabular}{|l|c|c|}
\hline & PT passengers & Car drivers \\
\hline Bus frequency & 72 & 31 \\
\hline Reliability & 15 & 14 \\
\hline Location of bus stops & 6 & 7 \\
\hline Travel time & 45 & 12 \\
\hline Night services & 27 & 8 \\
\hline Comfort (on the bus) & 51 & 18 \\
\hline Better information & 6 & 2 \\
\hline Other & 4 & 3 \\
\hline None of the above & 7 & 1 \\
\hline Not use of PT & & 17 \\
\hline
\end{tabular}

The evaluation of the PT system of Thessaloniki was also performed in the framework of another questionnaire-based survey [12], in the period 
December 2004 to May 2005. The survey concerning the bus passengers took place at bus stops in the city center and its surroundings. Bus transfer stations like the IKEA station and the KTEL coach station were also included in the survey. The survey concerning the non-PT users took place outside two parking stations in the city centre. A number of 249 valid questionnaires were collected (167 refer to PT users and the rest 82 refer to non PT users). The results concerning the bus passengers showed that almost $80 \%$ of them had stated that they had made a transfer during a typical daily trip. It is interesting to notice that, $62 \%$ had made one transfer, $35 \%$ two, and only $3 \%$ had made more than 2 transfers. A percentage of $76 \%$ stated that they walked for less than 5 minutes from their origin to the transfer bus station or bus stop. The average bus-waiting time for transfer is presented in Table 3 while the level of satisfaction as perceived by the passengers for various elements of the PT system is presented in Table 4.

Table 3: $\quad$ Average bus-waiting time for transfer.

\begin{tabular}{|c|c|}
\hline Waiting time & Percentage of passengers \\
\hline$<5$ minutes & $26 \%$ \\
\hline $5-10$ minutes & $53 \%$ \\
\hline $10-15$ minutes & $15 \%$ \\
\hline$>15$ minutes & $6 \%$ \\
\hline
\end{tabular}

A percentage of almost $96 \%$ of the passengers stated that access of the PT system was not easy for people with special needs. It is also interesting to notice that passengers at a percentage of $68 \%$ stated that they would continue to use the PT system. Finally a percentage of almost $60 \%$ stated that they owned a private car. Table 5 presents the factors that would positively affect the choice of PT from private car drivers. A percentage of $30 \%$ stated that they would definitely use the PT system in case that the necessary changes (according to their opinion) were made.

Table 4: Level of satisfaction as perceived by the passengers for various elements of the PT system.

\begin{tabular}{|l|c|c|c|c|}
\hline & \multicolumn{3}{|c|}{ Level of satisfaction } \\
\hline PT elements & Not at all & Little & Enough & $\begin{array}{c}\text { More than } \\
\text { enough }\end{array}$ \\
\hline $\begin{array}{l}\text { Comfort at bus stops and } \\
\text { vehicles }\end{array}$ & $24 \%$ & $53 \%$ & $23 \%$ & $0 \%$ \\
\hline $\begin{array}{l}\text { Cleanliness of bus stops } \\
\text { and vehicles }\end{array}$ & $18 \%$ & $38 \%$ & $42 \%$ & $2 \%$ \\
\hline $\begin{array}{l}\text { Information at bus stops } \\
\text { and vehicles }\end{array}$ & $16 \%$ & $44 \%$ & $37 \%$ & $3 \%$ \\
\hline Reliability of service & $10 \%$ & $51 \%$ & $37 \%$ & $2 \%$ \\
\hline Personnel behavior & $7 \%$ & $28 \%$ & $59 \%$ & $6 \%$ \\
\hline Trip duration & $16 \%$ & $36 \%$ & $44 \%$ & $4 \%$ \\
\hline
\end{tabular}


Table 5: Factors that would positively affect the choice of PT from car drivers.

\begin{tabular}{|l|c|}
\hline Factors & Responses (\%) \\
\hline Comfort at bus stops and vehicles & $25 \%$ \\
\hline Security at bus stops and vehicles & $8 \%$ \\
\hline Reliability of service & $9 \%$ \\
\hline Bus frequency & $30 \%$ \\
\hline Personnel behavior & $4 \%$ \\
\hline Cleanliness of bus stops and vehicles & $1 \%$ \\
\hline Better information at bus stops and vehicles & $1 \%$ \\
\hline Short travel time & $17 \%$ \\
\hline Night service & $4 \%$ \\
\hline Other & $1 \%$ \\
\hline
\end{tabular}

The question of whether all the above-mentioned reasons are justifiable is not easy to be answered. For example, information to the passengers is provided through printed timetables and maps at the bus stops of the Thessaloniki PT network. A questionnaire-based survey was carried out in the year 2005 concerning the use of these timetables and maps in Thessaloniki [13]. A number of 250 valid questionnaires were collected (160 of which were collected in the bus transfers stations of IKEA, NRS and KTEL). According to the results a percentage of $60 \%$ said that they did not look at timetables and maps, $24 \%$ said that they occasionally looked, $8 \%$ said that they often looked and finally a percentage of $8 \%$ said that they usually looked. It is therefore obvious that most of the people gave negative responses.

\section{Discussion}

The results of the surveys have shown that "reliability", "bus frequency", "comfort" and "direct service" are the most important factors for passengers at the bus station, which is located at the airport. The evaluation of the whole Public Transport system of the city by the bus passengers have shown that "bus frequency", "comfort (on the bus)" and "travel time" significantly affect their decision. It is interesting to notice that for both bus passengers and car drivers, factors like "location of bus stops" and "better information" are of low priority. When only the passengers of the bus transfer stations are considered, it seems that "better information" plays an important role and that other reasons with high priority are also appear in the list like "night trips". Walking time to the bus transfer stations or bus stops for the majority of the passengers $(76 \%)$ is less than 5 minutes. The average bus-waiting time for transfer is less than 10 minutes for the $79 \%$ of the passengers. Finally, car drivers rank "bus frequency" and "comfort at bus stops and vehicles" as their first priorities. 


\section{References}

[1] Stern, R., Booz Allen \& Hamilton, Inc., Passenger Transfer System Review, A Synthesis of Transit Practice, TCRP Synthesis 19, Transit Cooperative Research Program, Transportation Research Board, National Research Council, National Academy Press, Washington, D.C. 1996.

[2] Giannopoulos G.A., Urban Public Transport, Volume 1, $2^{\text {nd }}$ Edition, Papasotiriou, pp. 91-92, 1994.

[3] Wilson, F.R., Journey to work-modal split. London. Maclaren and Sons Ltd. 1967.

[4] Koushki, P.A., Al-Saleh, O.I. \& Al-Lumaia, M., On management's awareness of transit passenger needs, Transport Policy, 10, pp. 17-26, 2003.

[5] Mitchell, C. \& Miller, M.A., A Field Survey of Site Visits to Passenger Intermodal Transfer Facilities in California, PATH Technical Note 20011, A Report for MOU 375, Institute of Transportation Studies, University of California, Berkeley, California Partners for Advanced Transit and Highways, 2000.

[6] Urban Transport Organisation of Thessaloniki (OASTH), www.oasth.gr

[7] Giorgou, A. \& Konstantinidou, C., Investigation of the operational characteristics of the NRS and IKEA bus transfer stations, Diploma Thesis, Supervisor: S. Basbas, Faculty of Rural \& Surveying Engineering, Aristotle University of Thessaloniki, 2004.

[8] Davi, K. \& Soultatou E., Investigation of the capabilities for the improvement of service offered by the Public Transport System to the Thessaloniki "Makedonia" Airport, Diploma Thesis, Supervisor: S. Basbas, Faculty of Rural \& Surveying Engineering, Aristotle University of Thessaloniki, 2004.

[9] Laboratory of Transport Engineering, Civil Engineering Department of A.U.Th., Research on trip characteristics in Thessaloniki Greater Area, Thessaloniki, 1989.

[10] Trademco, Denco, Aggelidis, Truth, Infodim, SDG, WS-Atkins, General Transportation Study of Thessaloniki Metropolitan Area, Thessaloniki, 1998.

[11] Kroupa, E., Investigation of trip and passenger's characteristics, M.Sc. Thesis, Supervisor: Taxiltaris C., M.Sc. Course on Design, Organisation and Management of Transport Systems, Aristotle University of Thessaloniki, 2005.

[12] Skepastidou, A. \& Tsiberidou, K., Investigation of the operational characteristics of the OASTH bus lines and of the trip characteristics, Diploma Thesis, Supervisors: C. Taxiltaris \& S. Basbas, Faculty of Rural \& Surveying Engineering, Aristotle University of Thessaloniki, 2005.

[13] Konstantinidou, C., Can People Read Bus Timetables and Maps in Thessaloniki, Greece, M.Sc. Thesis, Supervisor: P. Firmin, M.Sc. (Eng) Course on Transport Planning and Engineering, Institute for Transport Studies, The University of Leeds, 2005. 